\title{
Oxidative damage parameters in renal tissues of aged and young rats based on gender
}

This article was published in the following Dove Press journal:

Clinical Interventions in Aging

27 June 2013

Number of times this article has been viewed

\author{
Duygu Uzun' \\ Gülcan Güntaș Korkmaz \\ Mustafa Erinç Sitar ${ }^{3}$ \\ Tamer Cebe ${ }^{4}$ \\ Karolin Yanar ${ }^{3}$ \\ Ufuk Çakatay ${ }^{3}$ \\ Seval Aydın ${ }^{3}$ \\ 'Istanbul University, Istanbul Faculty \\ of Medicine, Istanbul, Turkey; \\ ${ }^{2}$ Kırklareli University, School of \\ Health, Kırklareli, Turkey; ${ }^{3}$ sstanbul \\ University, Cerrahpașa Faculty of \\ Medicine, Department of Medical \\ Biochemistry, Istanbul, Turkey; \\ ${ }^{4}$ Istanbul University Cerrahpașa \\ Faculty of Medicine, Istanbul, Turkey
}

Purpose: Aging is characterized by a gradual functional decrease of all systems including the kidneys. Growing evidence links altered lipid protein redox-homeostasis with renal dysfunction. The effect of sexual dimorphism on the lipid protein redox-homeostasis mechanisms in the aging kidney is obscure. In the current study, we aimed to investigate redox homeostasis as it related to sexual dimorphism on protein oxidation and lipid peroxidation parameters, as protein carbonyl (PCO), total thiol (T-SH), advanced oxidation protein products (AOPP), malondialdehyde, glutathione (GSH), and superoxide dismutase (SOD) activity, as potential aging biomarkers, which may contribute to an analysis of the free radical theory of aging.

Materials and methods: The study was carried out with 16 naturally aged rats ( 24 months old; eight males and eight females) and their corresponding young rat groups as controls (6 months old; eight males and eight females). All of the aforementioned parameters (PCO, T-SH, AOPP, MDA, GSH, SOD) were measured manually instead of automated devices or ELISA kits.

Results: PCO, AOPP, and malondialdehyde levels in aged rats were significantly higher in the older rat group than in the younger rat group, whereas SOD activities were significantly lower in old rats. T-SH levels were not significantly different in male groups; however, T-SH levels were lower in the aged female group than in the young female control group. In addition, GSH levels were significantly different between the aged rat group and the corresponding young control group for both genders.

Conclusion: With respect to PCO and AOPP, impaired redox homeostasis is substantially more prominent in males than females. The decrease of G-SH levels in male groups could be attributed to stabilizing the redox status of protein thiol groups by the depletion of the GSH groups. Considering the results, the renal tissue proteins and lipids in different genders may have different susceptibilities to oxidative damage.

Keywords: lipid peroxidation, protein oxidation, radicals, renal aging

\section{Introduction}

The entire world is undergoing a progressive phenomenon where society has a larger number of older adults demanding to live healthy lives, which is occurring together with increasing public health costs. The aging process affects all organs, including the kidneys. As part of this inevitable process, progressive scarring and a measurable decline in renal function occur in most people over time., A number of structural changes occur in the kidneys with aging. The aging kidney is characterized by a loss of renal mass, arterial sclerosis, arteriolar hyalinosis, an increased number of sclerotic glomeruli, a loss of tubules, and interstitial fibrosis. The pathogenesis of aging-associated structural changes is not completely understood. ${ }^{2}$
Correspondence: Seval Aydın Faculty of Medicine, Department of Medical Biochemistry, 34098, Cerrahpașa, Fatih, Istanbul Tel +90 2l 2 4l43000 ext 21514 Fax +90 2126320050

Email aydinsevalctf@gmail.com 
Clinical factors, including hypertension, diabetes mellitus, obesity, abnormal lipid levels and vitamin D deficiency have been associated with increasing renal sclerosis with aging. ${ }^{1,2}$ In addition to the aforementioned pathologic states, tissue factors such as protein, deoxyribonucleic acid, and lipid oxidation products are associated with renal aging. ${ }^{3,4}$

Growing evidence has linked altered lipid protein redoxhomeostasis (LPRH), antioxidant enzyme expression, and renal dysfunction. ${ }^{3,4}$ Aging causes decreased gonadal hormone levels in systemic circulation, ${ }^{5,6}$ as well as altered systemic redox homeostasis of plasma proteins in both genders $;^{7}$ hence, the possible changes in this function may affect the LPRH of the aging kidney. The effect of gender dimorphism on LPRH mechanisms in the aging kidney is still an unclear issue.

Renal biopsy is only recommended for selected patients with kidney diseases. It is well known that elderly people in both genders, who have generally suffered from various aforementioned clinical morbidities or who may be using some medications that interfere with the accuracy of the result of renal biopsies and other diagnostic tools, compel us to choose other less invasive diagnostic tests other than renal biopsy in aged rats. Our aim was to identify the difference between a broad set of oxidative stress parameters (Table 1) to enlighten a road map for a possible discovery of aging biomarkers in order to differentiate chronological aging from biological aging, as well as to contribute to the literature of experiment-based evidence on an oxidative stress theory of aging. ${ }^{8}$

Table I Oxidative stress parameters currently being researched and their descriptions

\begin{tabular}{|c|c|}
\hline $\begin{array}{l}\text { Abbreviation of } \\
\text { the parameter }\end{array}$ & Characteristics \\
\hline $\mathrm{PCO}$ & $\begin{array}{l}\text { Chemically stable markers for oxidative stress } \\
\text { in biologic samples. } 9\end{array}$ \\
\hline AOPP & $\begin{array}{l}\text { Novel oxidative stress biomarkers detected } \\
\text { in plasma of chronic uremic patients for the } \\
\text { first time, as indices of oxidant-mediated } \\
\text { protein damage. }^{10}\end{array}$ \\
\hline $\mathrm{T}-\mathrm{SH}$ & $\begin{array}{l}\text { Organic compounds containing the sulfhydryl } \\
(-\mathrm{SH}) \text { groups, which are crucial in redox } \\
\text { signaling and control antioxidant protection." }\end{array}$ \\
\hline MDA & Reactive indicator of lipid peroxidation. ${ }^{12}$ \\
\hline Cu-Zn SOD & $\begin{array}{l}\text { Significant antioxidant defense in many types } \\
\text { of mammalian cells exposed to oxygen. }{ }^{13}\end{array}$ \\
\hline GSH & $\begin{array}{l}\text { One of the most abundant nonprotein thiol } \\
\text { groups in mammalian cells. }{ }^{13}\end{array}$ \\
\hline
\end{tabular}

Abbreviations: PCO, protein carbonyls; AOPP, advanced oxidation protein products; T-SH, total thiol groups; MDA, malondialdehyde; SOD, superoxide dismutase; GSH, reduced glutathione.

\section{Materials and methods}

\section{Experimental animals and procedures}

Ten male and 13 female aged Sprague Dawley rats (24 months of age) and corresponding young controls (eight females, eight males; 6 months of age) were kindly provided by Professor Tuncay Altuğ (deceased) from the Experimental Animal Research and Breeding Laboratory, Cerrahpaşa Medical Faculty, Istanbul University, Istanbul, Turkey. All animals were kept in the same unit at a constant temperature $\left(22^{\circ} \mathrm{C} \pm 1{ }^{\circ} \mathrm{C}\right)$ under a 12 -hour light/dark cycle. Food and fresh tap water were supplied ad libitum throughout the experiment. All of the experimental studies were conducted in accordance with "Recommendations on the Establishment of Animal Experimental Guidelines," and ethical procedures were conducted under Reduction, Replacement and Refinement (the 3 Rs rule). All rats were weighed at the same time and food and water were monitored daily throughout the study period. A total of eleven neoplasms were observed in seven (two males and five females) of the 23 aged rats during the sacrification period. The study was carried out with the remaining 16 aged (eight males, eight female) rats together with the 16 corresponding younger rats.

\section{Chemicals and apparatuses}

Chemicals and solvents used in the experiments were of the highest purity and analytical grade. All chemicals and reagents were purchased from Merck KGaA (Darmstadt, Germany) or Sigma-Aldrich (St Louis, MO, USA). Deionized water was used in the analytical procedures. All reagents were stored at $+4^{\circ} \mathrm{C}$. The reagents were maintained in equilibrium at room temperature for 0.5 hours before use. All centrifugation procedures were performed with a Sigma 3-18 KS centrifuge (SIGMA Laborzentrifugen $\mathrm{GmbH}$, Osterode am Harz, Germany). Protein oxidation and other oxidative stress parameters were measured by using the Biotek Synergy ${ }^{\mathrm{TM}}$ H1 Hybrid Multi-Mode Microplate Reader (BioTek US, Winooski, VT, USA).

\section{Preparation of tissue samples}

The kidney tissue samples, which were obtained from the rats under deep anesthesia with intraperitoneally administered sodium pentothal, were washed in cooled $0.9 \% \mathrm{NaCl}$ and placed on an ice-cold plate. The samples were then immediately frozen in liquid $\mathrm{N}_{2}$ until they were homogenized. Tissue $(200 \mathrm{mg}$ ) samples were homogenized manually in $2 \mathrm{~mL}$ of homogenizing buffer $\left(100 \mathrm{mM} \mathrm{KH}_{2} \mathrm{PO}_{4}-\mathrm{K}_{2} \mathrm{HPO}_{4}\right.$, $\mathrm{pH} 7.4$, plus $0.1 \%[\mathrm{w} / \mathrm{v}]$ digitonin). Homogenates that were obtained from the kidney tissues were centrifuged at $5000 \mathrm{~g}$ 
for 10 minutes, and various analytes of the supernatant fraction were examined.

\section{Assay of protein carbonyl groups}

Protein carbonyl (PCO) groups were measured spectrophotometrically by using the Reznick and Packer method. ${ }^{14} \mathrm{PCO}$ groups react with 2, 4-dinitrophenylhydrazine (DNPH) to generate chromophoric dinitrophenylhydrazones. DNPH was dissolved in $\mathrm{HCl}$, and after DNPH reaction, proteins were precipitated with an equal volume of $20 \%$ $(\mathrm{w} / \mathrm{v})$ trichloroacetic acid and washed three times with $4 \mathrm{~mL}$ of an ethanol/ethyl acetate mixture (1:1). Washing was done by the mechanical disruption of pellets in the washing solution using a small spatula, and repelleting by centrifugation at $6000 \mathrm{~g}$ for 5 minutes. Finally, the protein precipitates were dissolved in $6 \mathrm{M}$-guanidine- $\mathrm{HCl}$ solution and the absorbance values were measured at $360 \mathrm{~nm}$ using the molar extinction coefficient of DNPH, $\varepsilon=22,000 \mathrm{M}^{-1}$ $\mathrm{cm}^{-1}$.

\section{Assay of total thiol groups}

A part $(125 \mu \mathrm{L})$ of the supernatant fraction that was obtained by the centrifugation of the homogenates was mixed in $5 \mathrm{~mL}$ test tubes with $375 \mu \mathrm{L}$ of $0.2 \mathrm{M}$ Tris buffer, $\mathrm{pH} 8.2$, and $25 \mu \mathrm{L}$ of $0.01 \mathrm{M}$ 5,5-dithiobis 2-nitrobenzoic acid (DTNB). The volume of the mixture was increased up to $2.5 \mathrm{~mL}$ with $1975 \mu \mathrm{L}$ of absolute methanol. A reagent blank (without sample) and a sample blank (without DTNB) were prepared in a similar manner. The test tubes were covered with rubber caps, color was formed in 15 minutes, and the mixtures were centrifuged at approximately $3000 \mathrm{~g}$ at room temperature for 15 minutes. The absorbance values of the supernatant fractions were read at $412 \mathrm{~nm}$ with a spectrophotometer. ${ }^{15}$ The value of molar extinction coefficient of total thiol (T-SH) groups at wavelength $412 \mathrm{~nm}$ is approximately $\varepsilon=13,100 \mathrm{M}^{-1} \mathrm{~cm}^{-1}$.

\section{Assay of advanced oxidation protein products}

Spectrophotometric determination of advanced oxidation protein products (AOPP) was performed by a modification of Witko, Nguyen, and Descamps-Latscha's method. ${ }^{16}$ Samples were prepared in the following procedure: $100 \mu \mathrm{L}$ of supernatant was diluted 1:5 in phosphate buffered saline (PBS), $5 \mu \mathrm{L}$ of $1.16 \mathrm{M}$ potassium iodide was then added to each tube, followed by $10 \mu \mathrm{L}$ acetic acid two minutes later. The absorbance of the newly formed mixture was immediately measured at $340 \mathrm{~nm}$ by using a blank as reference containing
$1000 \mu \mathrm{L}$ of PBS, $50 \mu \mathrm{L}$ of Potassium Iyodide (KI), and $100 \mu \mathrm{L}$ of acetic acid. The chloramine-T absorbance at $340 \mathrm{~nm}$ was observed to be linear within the range of $0 \mu \mathrm{mol} / \mathrm{L}$ to $100 \mu \mathrm{mol} / \mathrm{L}$. AOPP concentrations were expressed as micromoles per liter of chloramine-T equivalents.

\section{Assay of malondialdehyde}

The rate of lipid peroxidation was determined by the procedure of Buege and Aust. ${ }^{17}$ One of the major secondary products of lipid peroxidation is malondialdehyde (MDA). MDA, along with other byproducts, react with thiobarbituric acid to generate a colored product, which absorbs maximally at $535 \mathrm{~nm}$, representing the color produced by all the thiobarbituric acid reactive substances.

\section{Assay of glutathione}

Cayman's (Cayman Chemical Company, Ann Arbor, MI, USA) glutathione (GSH) assay kit utilizes an enzymatic recycling method, using GSH reductase, for the quantification of GSH. The thiol group of GSH reacts with DTNB (Ellman's reagent) and produces a yellow-colored 5-thio-nitrobenzoic acid (TNB). The mixed disulfide, (GSTNB), that is concomitantly produced, is reduced by GSH reductase to recycle the GSH and produce more TNB. The rate of TNB production is directly proportional to the concentration of GSH in the deproteinized sample.

\section{Assay of superoxide dismutase activity}

Determination of superoxide dismutase (Cu-Zn SOD) (EC 1.15.1.1) activity was performed in supernatant fractions based on the method developed by Sun et al. ${ }^{18}$ This assay involves the inhibition of nitroblue tetrazolium reduction, with xanthine oxidase used as a superoxide generator. One unit of Superoxide Dismutase (SOD), is defined as the amount of enzyme needed to exhibit a $50 \%$ dismutation of superoxide radical.

\section{Statistical analysis}

Data are expressed as the mean \pm standard error of the mean for eight animals in each group. Differences between the groups were assessed by one-way analysis of variance using the SPSS software package for Windows (IBM Corporation, Armonk, NY, USA). Post hoc testing was performed for intergroup comparisons using the least significance difference test. Post hoc tests were conducted by the Bonferroni-Dunn test. A probability value of less than 0.05 was considered statistically significant. 


\section{Results}

In our experimental observations, which have been conducted within the animal husbandry conditions provided by the Experimental Animal Research and Breeding Laboratory, Cerrahpaşa Medical Faculty, Istanbul University, Istanbul, Turkey, the median lifespan of the male rat was found to be 26 months and its maximum lifespan was 30 months. On the other hand, the median lifespan of the female rat turned out to be 28 months and its maximum lifespan was 33 months.

PCO and AOPP levels in the aged male rats were significantly higher than those in the young male group (Figures 1 and 2). T-SH levels were not found to be different between both the young and old male rats (Figure 3). In aged male rats, MDA levels were found to be higher than among their corresponding young controls (Figure 4). Cu-Zn SOD activities of the aged male rats were significantly lower compared to those of the young male rats (Figure 5). GSH levels were found to be different between the aged male group and the corresponding young controls (Figure 6).

In addition to the male groups, PCO and AOPP levels in the aged female rats were significantly higher than those in the group of young female rats (Figures 1 and 2). T-SH levels were found to be lower among the aged female group (Figure 3). MDA levels were higher in the aged female rats than in the young female rats (Figure 4), whereas the GSH levels were found to be lower in the aged female rats and the corresponding young controls (Figure 6). The activity of $\mathrm{Cu}-\mathrm{Zn}$ SOD among the aged female rats was significantly lower when compared with that of the young female rats (Figure 5).

\section{Discussion}

The biology of human aging is a highly active and rapidly evolving field. At this point in time, there are as many

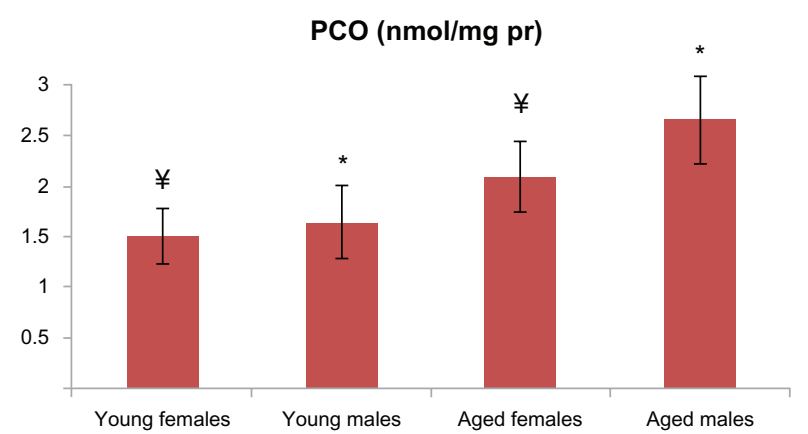

Figure I PCO levels in aged male and female rats were significantly higher than those in the young male and female groups $(P<0.001$ for males; $P<0.01$ for females). There is a statistically significant difference with $*$ representing male and $¥$ representing females.

Abbreviations: PCO, protein carbonyl; pr, protein.

\section{AOPP $(\mu \mathrm{mol} / \mathrm{mg} \mathrm{pr})$}

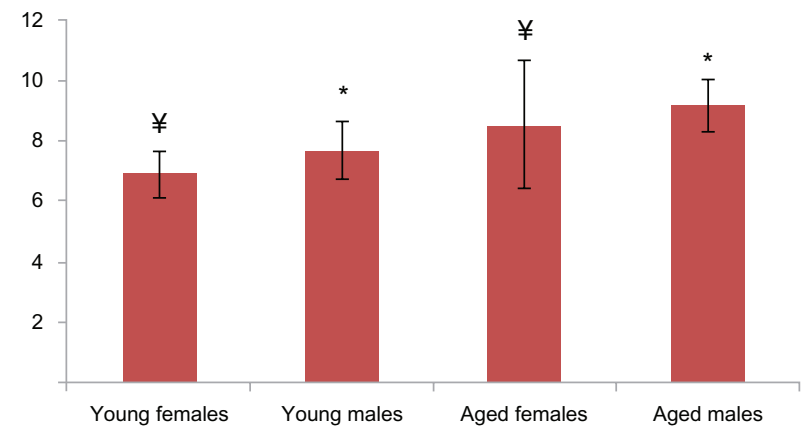

Figure 2 AOPP levels in aged male and female rats were significantly higher than those in the young male and female groups $(P<0.001$ for males and $P<0.01$ for females). There is a statistically significant difference where $*$ represents males and $¥$ represents females.

Abbreviation: AOPP, advanced oxidation protein products.

questions as there are answers; however, an increasing number of inquiries have not resulted in sufficient answers, and these questions are mostly related to the genesis of physiologic aging. Although all organs age in a different time manner, renal aging is an unsolved health problem for the whole society. The kidney is also highly vascular and is impacted by aging of the vascular system with respect to the development of atherosclerosis and hypertension. It has been known for over 50 years that renal functions decline with age, and glomerulosclerosis increases with age even in the absence of comorbidities. ${ }^{19}$ Females develop lower levels of age-dependent renal function loss than males, which may be in part due to the protective effects of estrogen on cardiorenal function. However, the effect of androgen levels on cardiovascular-renal health is controversial. ${ }^{20}$

Oxidative stress is linked to the production of reactive lipid aldehydes that nonenzymatically alkylate cysteine, histidine, or lysine residues in a reaction termed protein

\section{T-SH (nmol/mg pr)}

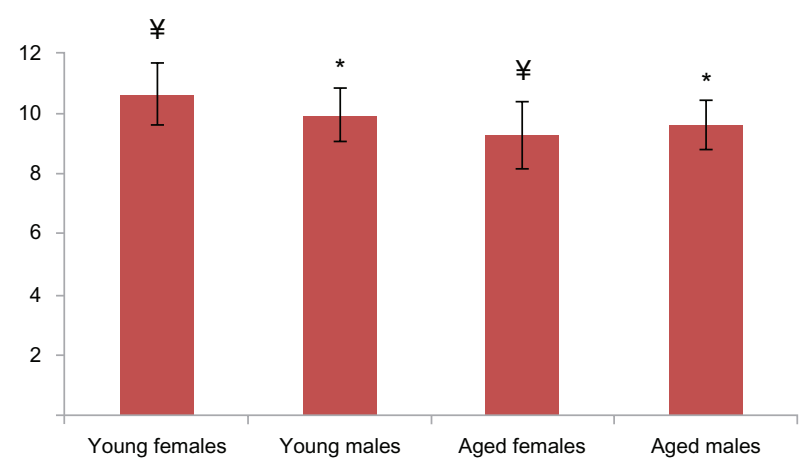

Figure $3 \mathrm{~T}$-SH levels were not found to be different between the male groups. Note: On the other hand, T-SH levels were found to be lower in the aged female group ( $P<0.05$ for the female groups). There is a statistically significant difference with $*$ representing male and $¥$ representing females.

Abbreviation: T-SH, total thiol. 
MDA (nmol/mg pr)

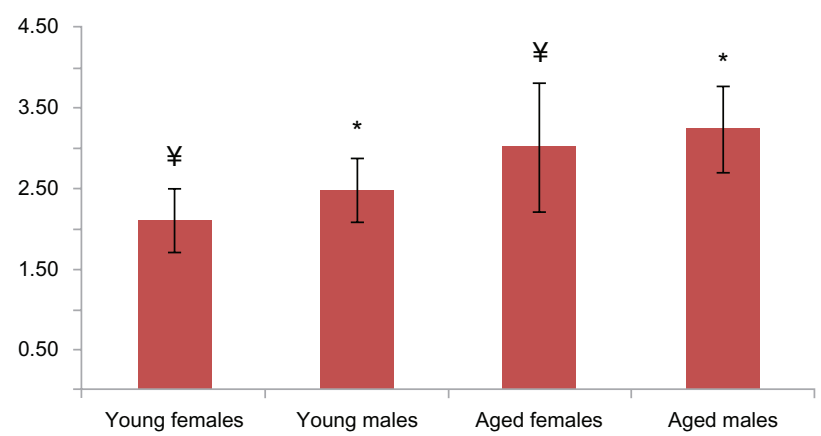

Figure $4 \mathrm{In}$ aged male rats, MDA levels were found to be higher than among the young male rats, which was also evident for females $(P<0.05$ for both males and females). There is a statistically significant difference with $*$ representing male and $¥$ representing females.

Abbreviations: MDA, malondialdehyde; pr, protein.

carbonylation. ${ }^{20}$ Reactive lipid aldehydes such as MDA and their derivatives are detoxified via a variety of phase 1 and phase 2 systems, and when antioxidant defenses are compromised or oxidative conditions are increased, protein carbonylation (a formation of the PCO groups) is increased. Identifying the carbonylation of proteins is critical for cellular homeostasis, and it could potentially provide important information concerning molecular mechanisms underlying the development and progression of aging and diseases linked to oxidative stress. ${ }^{21}$

Age-related renal insufficiency has important implications due to the impaired redox homeostasis of proteins. ${ }^{3}$ Oxidative modifications of cellular proteins, such as PCO and AOPP formation, usually result in a loss of protein function. When aged male and female rats are compared to their young controls with respect to PCO and AOPP, the impaired redox homeostasis on renal tissue proteins is more prominent in males than females. Therefore, the cysteine residues of

\section{Cu-Zn SOD (superoxide dismutase) activity}

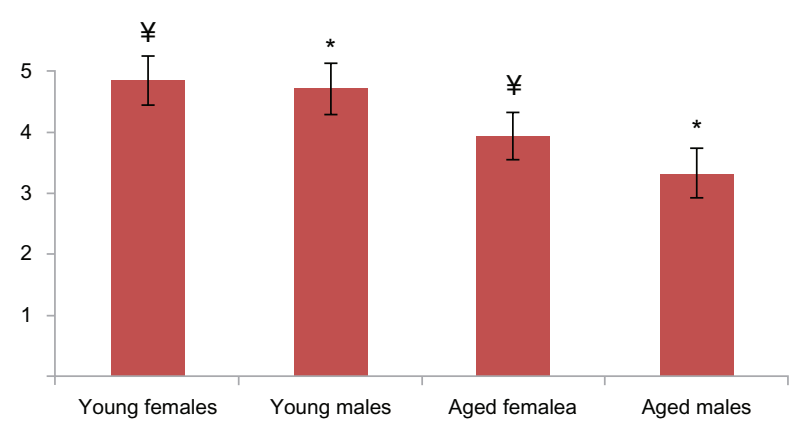

Figure $5 \mathrm{Cu}-\mathrm{Zn}$ SOD activities of aged male and female rats were significantly lower when compared with those of the young rats $(P<0.001$ for both groups). There is a statistically significant difference with $*$ representing males and $¥$ representing females.

Abbreviation: $\mathrm{Cu}-\mathrm{Zn}$ SOD, superoxide dismutase.

\section{GSH ( $\mu \mathrm{mol} / \mathrm{mg} \mathrm{pr})$}

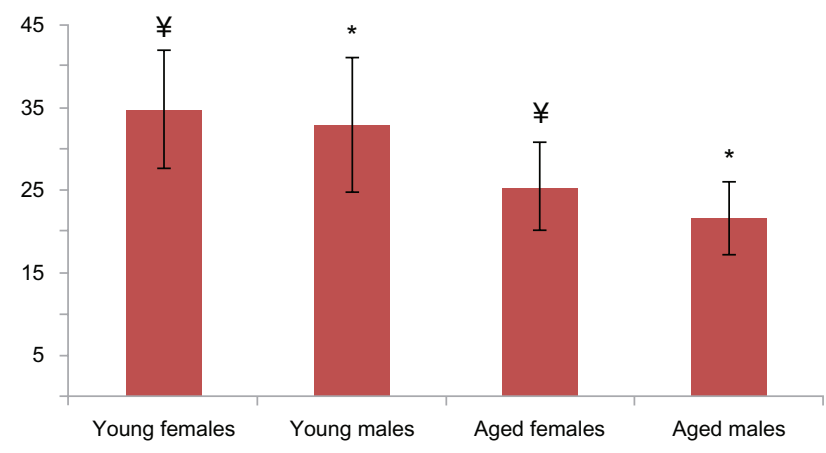

Figure 6 GSH levels were found to be different between the aged male rats and the corresponding young controls $(P<0.01)$; GSH levels were found to be lower in the aged female rats and the corresponding young controls $(P<0.05)$. There is a statistically significant difference with $*$ representing male and $¥$ representing females. Abbreviations: GSH, glutathione; pr, protein.

some proteins act as sensors of redox conditions and can be oxidized in a reversible manner. ${ }^{22,23}$ Hydrogen peroxide is now considered to act as a second messenger, specifically on the thiol groups, which are the direct targets of the oxidant signal. Central to redox signaling processes are the GSH and thioredoxin systems, which control hydrogen peroxide levels and thus the thiol/disulfide balance. ${ }^{23} \mathrm{GSH}$ inhibits free radical-mediated injury by eliminating reactive oxygen species and protects T-SH groups from oxidation by serving as a biological redox agent. The lack of a significant difference on the levels of the T-SH groups between the aged and young male rats may be related to the compensatory and critical role of GSH on protein redox regulation. The prominent decrease in the GSH levels among the male groups may be related to a change in the redox status of protein thiol groups.

Diseases of chronic oxidative stress and aging involve the accumulation of reactive aldehydes such as MDA. The generation of reactive aldehydes via lipid peroxidation results in protein carbonylation. ${ }^{24}$ MDA levels were found to be significantly higher in both genders of rats when compared to their corresponding young controls. We are of the conviction that the increased lipid peroxidation rate, which appears to occur in both genders of rats, may be an enhancing factor in the propagation of protein oxidation, as indicated by the PCO and AOPP levels in renal tissue. The variations found between the statistically significant levels of T-SH in the aged male and female rats should be mostly attributed to the role that gender-related factors play in protecting aged female rats against the lipid peroxidation of the kidney tissues. In addition to this finding, we observed that the number of female rats that presented with tumors was almost higher than that of males, of which the difference was accounted for chiefly by the high incidence of mammary tumors in the 
females. Urinary system tumors were observed in the two males, but not in the females.

It has been previously shown that $\mathrm{Cu}-\mathrm{Zn}$ SOD activities in the serum and kidney tissues of experimental animals are regulated by the aging process. ${ }^{25,26}$ Decreased activity of $\mathrm{Cu}-\mathrm{Zn}$ SOD would be expected to increase the susceptibility of the aging kidney tissues to oxidative injury in male and female rats. On the other hand, there are no established data or explanations in the current literature as to why the plasma $\mathrm{Cu}-\mathrm{Zn}$ SOD activities among both genders of aged rats differ from their corresponding young controls.

\section{Conclusion}

Considering the results of the current study, the renal tissue proteins among the different genders may have different susceptibilities to oxidative protein damage. The observed differences could be attributed to the aging processes, genderrelated hormonal status, and altered cellular homeostatic mechanisms. The statistically significant variations found between the aged male and female rats should be mostly referred to by the gender-related factors that could play a role in protecting the aged female rats against oxidative damage of the kidney tissues. Our findings can also support the idea that gender is a crucial feature for redox status of renal proteins in aged rats.

Though there are many answers that have been provided by researchers, there are still questions asking how living cells respond to oxidative stress or manage to adopt it in a deeper and more detailed manner for theurapathic point of view. The genderrelated data on these oxidative protein damage parameters in aged rats could be quite beneficial in studies of aging-related disorders like type 2 diabetes mellitus, urinary incontinence, renovascular diseases, or even renal malignancies, and in the future, these data can lead to possible therapeutic interventions developed from a protein oxidation point of view.

\section{Acknowledgments}

In memoriam: this paper is dedicated to the memory of Professor Tuncay Altuğ, Experimental Animal-Research and Breeding Laboratory, Istanbul University, Cerrahpaşa Faculty of Medicine, who kindly provided experimental animals for our current research. Duygu Uzun and Tamer Cebe, are medical students at Istanbul University, Turkey, Istanbul.

\section{Disclosure}

The authors report no conflicts of interest in this work.

\section{References}

1. Choudhury D, Levi M. Kidney aging - inevitable or preventable? Nat Rev Nephrol. 2011;7(12):706-717.

2. Pannarale G, Carbone R, Del Mastro G, et al. The aging kidney: structural changes. J Nephrol. 2010;23 Suppl 15:S37-S40.

3. Aydin S, Yanar K, Atukeren P, et al. Comparison of oxidative stress biomarkers in renal tissues of D-galactose induced, naturally aged and young rats. Biogerontology. 2012;13(3):251-260.

4. Gomes P, Simão S, Silva E, et al. Aging increases oxidative stress and renal expression of oxidant and antioxidant enzymes that are associated with an increased trend in systolic blood pressure. Oxid Med Cell Longev. 2009;2(3):138-145.

5. Veldhuis JD. Aging and hormones of the hypothalamo-pituitary axis: gonadotropic axis in men and somatotropic axes in men and women. Ageing Res Rev. 2008;7(3):189-208.

6. Horstman AM, Dillon EL, Urban RJ, Sheffield-Moore M. The role of androgens and estrogens on healthy aging and longevity. J Gerontol A Biol Sci Med Sci. 2012;67(11):1140-1152.

7. Çakatay U, Aydın S, Yanar K, Uzun H. Gender-dependent variations in systemic biomarkers of oxidative protein, DNA, and lipid damage in aged rats. Aging Male. 2010;13(1):51-58.

8. Harman D. Aging: a theory based on free radical and radiation chemistry. J Gerontol. 1956;11(3):298-300.

9. Çakatay U. Protein redox-regulation mechanisms in aging. In: Bondy SC, Maise K, editors. Aging and Age-Related Disorders. New York, NY: Springer; 2010:1-24.

10. Witko-Sarsat V, Friedlander M, Capeillère-Blandin C, et al. Advanced oxidation protein products as a novel marker of oxidative stress in uremia. Kidney Int. 1996;49(5):1304-1313.

11. De Chiara B, Sedda V, Parolini M, et al. Plasma total cysteine and cardiovascular risk burden: action and interaction. Scientific World Journal. 2012;2012:303654.

12. Ergün Y, Kurutaş EB, Atalay F, Alici T. Effects of silibinin and ethanol on skeletal muscle ischemia-reperfusion injury. Acta Cir Bras. 2013; 28(3):179-184.

13. Li Y, Huang Y, Piao Y, et al. Protective effects of nuclear factor erythroid 2-related factor 2 on whole body heat stress-induced oxidative damage in the mouse testis. Reprod Biol Endocrinol. 2013;11:23.

14. Reznick AZ, Packer L. Oxidative damage to proteins: spectrophotometric method for carbonyl assay. Methods Enzymol. 1994;233:357-363.

15. Sedlak J, Lindsay RH. Estimation of total, protein-bound, and nonprotein sulfhydryl groups in tisue with Ellman's reagent. Anal Biochem. 1968;25(1):192-205.

16. Witko V, Nguyen AT, Descamps-Latscha B. Microtiter plate assay for phagocyte derived taurine-chloramines. J Clin Lab Anal. 1992;6(1): $47-53$.

17. Buege JA, Aust SD. Microsomal lipid peroxidation. Methods Enzymol. 1978;52:302-310.

18. Sun Y, Oberley LW, Li Y. A simple method for clinical assay of superoxide dismutase. Clin Chem. 1988;34(3):497-500.

19. Wiggins J. Why do our kidneys get old? Nephron Exp Nephrol. 2011; 119 Suppl 1:e1-e5.

20. Baylis C. Sexual dimorphism: the aging kidney, involvement of nitric oxide deficiency, and angiotensin II overactivity. J Gerontol A Biol Sci Med Sci. 2012;67(12):1365-1372.

21. Baraibar MA, Liu L, Ahmed EK, Friguet B. Protein oxidative damage at the crossroads of cellular senescence, aging, and age-related diseases. Oxid Med Cell Longev. 2012;2012:919832.

22. Curtis JM, Hahn WS, Long EK, Burrill JS, Arriaga EA, Bernlohr DA. Protein carbonylation and metabolic control systems. Trends Endocrinol Metab. 2012;23(8):399-406.

23. Bindoli A, Rigobello MP. Principles in redox signaling: From chemistry to functional significance. Antioxid Redox Signal. 2013;18(13): $1557-1593$. 
24. Fritz KS, Petersen DR. Exploring the biology of lipid peroxidation-derived protein carbonylation. Chem Res Toxicol. 2011;24(9):1411-1419.

25. Comai S, Bertazzo A, Ragazzi E, Caparrotta L, Costa CV, Allegri G. Influence of age on $\mathrm{Cu} / \mathrm{Zn}$-superoxide dismutase and indole 2,3dioxygenase activities in rat tissues. Ital $J$ Biochem. 2005;54(3-4): 232-239.
26. Asghar M, George L, Lokhandwala MF. Exercise decreases oxidative stress and inflammation and restores renal dopamine D1 receptor function in old rats. Am J Physiol Renal Physiol. 2007;293(3):F914-F919.

Clinical Interventions in Aging

\section{Publish your work in this journal}

Clinical Interventions in Aging is an international, peer-reviewed journal focusing on evidence-based reports on the value or lack thereof of treatments intended to prevent or delay the onset of maladaptive correlates of aging in human beings. This journal is indexed on PubMed Central, MedLine, the American Chemical Society's 'Chemical Abstracts

\section{Dovepress}

Service' (CAS), Scopus and the Elsevier Bibliographic databases. The manuscript management system is completely online and includes a very quick and fair peer-review system, which is all easy to use. Visit $\mathrm{http}: / /$ www.dovepress.com/testimonials.php to read real quotes from published authors.

Submit your manuscript here: http://www.dovepress.com/clinical-interventions-in-aging-journal 